\title{
Analysis on the Contradiction between the Difficult Employment of College Students and Shortage of MigrantWorkers
}

\author{
TianqiHuang ${ }^{1, ~ a}$,MeixiaShi ${ }^{2, b}$ \\ ${ }^{1}$ School of Economics and Management, Beijing Jiaotong University, Beijing, China \\ ${ }^{2}$ School of Economics and Management, Beijing Jiaotong University, Beijing, China \\ a15120554@bjtu.edu.cn, ${ }^{b} 190352818 @ q q . c o m$
}

\begin{abstract}
Keywords:Difficulty in College Students' Employment,Shortage of Migrant Workers,Coordination Analysis
\end{abstract}

Abstract.This article analyzed "the difficult employment of college students and shortage of migrantworkers" and find out the reasons for this contradiction from coordination of the industrialstructure and employment structure, in order to find a way to solve this problem. Thephenomenon of "difficult employment of college students and shortage of migrant workers" areexplained from thevalue chain ofindustrial structure. Last part of the paper has put forward some countermeasuresand suggestions.

\section{Introduction}

In recent years, our country's labor market began to appear the phenomenon of the coexistence of a contradiction, on the one hand, the labor supply of college students couldn't find suitable jobs, whichleads to unemployment, another labor demanding enterprises to recruit suitable for labor brings about vacancy.

Since 2010, the coexistence of the difficult employment of college students and the labor shortage problem has become the focus of attention of the NPC and CPPCC.Thus a research onthecoexistence has not only the theory significance, but also the practical significance.

\section{Literature Review}

From a domestic perspective, the domestic scholars research the phenomenon mainly from the perspective of the specific situation of our country.

In the difficult employment of college students, mainly from the following three aspects:(1) the education system: Wang Yuanbo (2005)found that the contradictions between education structure andindustrial structure, area economic development imbalance are the main reasons for graduates' employment. (2) labor market segmentation and the relationship between supply and demand: Ma Tingqi and Peng Chen (2012)found that the current employment of college students face difficulties in practice is system of labor market in China a to institutional segmentation, industry segmentation and regional segmentation, supplemented by multiple segmentation pattern reflect (3) human capital theory and risk investment: Gao Yanan and Zhang Boyang (2012) consideredthat students some wrong concept of employment and occupation value orientation caused their employment.

In terms of employment of migrant workers, it focuses on the following aspects: (1)theinfluencing factors of rural labor force employment an countermeasures: Sun Yeliang and Zhu Lihua (2013) found that improving peasant workers' wages, the implementation of the reform of the household registration system is a feasible measure for solving the shortage of migrant workers; (2) migrant workers, employment discrimination and fair problem study: Gao $\mathrm{Na}$ (2012) found that employment discrimination of migrant workers make rural surplus labor to urban mobility will weaken, thereby reducing to the urban floating population. (3) the employment rights and protection of migrant workers: Li Changjian and Shao Jiangting (2010) pointed out that because of weakness and other external social reasons, farmers ought to get the effective protections.

In summary,the above researchrarely use the empirical analysis to quantitative analysis. 


\section{The status quo of the "The difficult employment of College students"}

In 2002 in 2013 this more than ten years, the number of college graduates in our country improves the nearly 5 times, in 2013 the number of university graduates in China had increased to 6.99 million, though, in recent years, college enrollment growth rate has slowed down, but the enrollment of absolute value is still rising trend. Table 1 describes college graduates employment rate and growth rate in 2002-2013.

Table 1.The college graduates' number,growth rate and employment rate in 2002-2013

\begin{tabular}{cccc}
\hline year & $\begin{array}{c}\text { graduates } \\
\text { number }\end{array}$ & growth rate & $\begin{array}{c}\text { employment } \\
\text { rate }\end{array}$ \\
\hline 2002 & 145 & $26.2 \%$ & $80 \%$ \\
2003 & 212 & $46.2 \%$ & $70 \%$ \\
2004 & 280 & $32.0 \%$ & $73 \%$ \\
2005 & 338 & $20.7 \%$ & $72.6 \%$ \\
2006 & 413 & $22.2 \%$ & $71.8 \%$ \\
2007 & 495 & $19.9 \%$ & $70.9 \%$ \\
2008 & 559 & $12.9 \%$ & $70 \%$ \\
2009 & 611 & $9.3 \%$ & $68 \%$ \\
2010 & 630 & $3.3 \%$ & $72.2 \%$ \\
2011 & 660 & $4.8 \%$ & $77.8 \%$ \\
2012 & 680 & $3.0 \%$ & $72.8 \%$ \\
2013 & 699 & $2.8 \%$ & $71.9 \%$ \\
\hline
\end{tabular}

Data source: official statistics of China Ministry of education

The above data show that in recent years, China's university graduates employment rate is not ideal, in addition to the employment rate in 2011 with a brief recovery, since 2003, the employment rate of college students is never more than $73 \%$. Although, from the beginning of 2010, increasing the amount of college graduates began to slow down, but still cannot ease the employment rate declining.

\section{The status quo of the "Shortage of migrant workers"}

According to the statistics report released by the Ministry of agriculture of China in 2009, it showed that China's rural labor force growth is negative, and scholars anticipate a few decades later, it will only continue to decline, as shownintable 2.

Table 2.The change trend of Chinese rural labor force (unit:100 million)

\begin{tabular}{c|c|c|c|c|c|c|c}
\hline year & $\mathbf{2 0 0 9}$ & $\mathbf{2 0 1 0}$ & $\mathbf{2 0 1 1}$ & $\mathbf{2 0 1 2}$ & $\mathbf{2 0 1 3}$ & $\mathbf{2 0 1 4}$ & $\mathbf{2 0 1 5}$ \\
\hline rural labor force & 4.94 & 4.89 & 4.84 & 4.78 & 4.72 & 4.64 & 4.56 \\
\hline year & $\mathbf{2 0 1 6}$ & $\mathbf{2 0 1 7}$ & $\mathbf{2 0 1 8}$ & $\mathbf{2 0 1 9}$ & $\mathbf{2 0 2 0}$ & $\mathbf{2 0 2 1}$ & $\mathbf{2 0 2 2}$ \\
\hline rural labor force & 4.13 & 3.76 & 3.36 & 2.93 & 2.6 & 2.39 & 2.21 \\
\hline
\end{tabular}

Data source: MinistryofAgriculture

Rural labor force absolute population decreased, and more than 30 years of reform and opening up the rural labor force transfer of a continuous, the number of rural surplus labor force in our country began to sharply reduce, our country rural labor force has entered into Limited surplus stage. 


\section{Empirical Analysis on the influence of industrial structure on employment elasticity}

Model building. With the adjustment of industrial structure in Zhejiang Province, the pulling effect on economic growth and the stimulating effect on national economic growth, take the first industry as an example, regression model is:

$$
\log \left(\text { agr_e } e_{t}\right)=c+b_{1} \log \left(a g r \_g d p_{t}\right)+b_{2} \log \left(\text { tot }_{g} g d p_{t}\right)+b_{3} \log \left(g_{d p}\right)+\varepsilon_{t} \text {. }
$$

agr_e $e_{t}$ is the first industry employment in Zhejiang Province,agr_gdp is the first industrial added value in Zhejiang Province, tot_gdp is the gross domestic product,gdp is the three industrial added value of Zhejiang.

\section{Empirical Research}

Table 3.Coefficient table

\begin{tabular}{cccc}
\hline & the first industry & the second industry & the third industry \\
\hline agr_gdp & 0.2635 & 0.6893 & -0.5634 \\
tot_gdp & -0.1923 & 0.1268 & 0.1189 \\
gdp & -0.3593 & -0.6835 & 0.6926 \\
$\mathrm{C}$ & 4.8891 & 2.2490 & 1.6947 \\
$\mathrm{R}_{\mathrm{t}}^{2}$ & 0.9986 & 0.9960 & 0.9936 \\
adjusted $R^{2}$ & 0.9973 & 0.9925 & 0.9928 \\
\hline
\end{tabular}

The first industry continues to release within the industry and the second industry and the third industry need to undertake the transfer of labor force to do further preparations. In the second industry,agr $g d p_{t}$ is 0.6893 , showing that employment growth is mainly achieved by increasing its output value within the department, but not by promoting the adjustment of industrial structures. The third industrial employment growth is mainly through the Zhejiang Province Economic Growth.

\section{Summary}

Taking promoting the upgrading ofmanufacturing industry, developing the tertiary industry, and speeding up the adjustment ofindustrial structure as breakthrough points is the fundamental way to resolve the currentstructural contradictions of the coexistence of "difficult employment of college students andshortage of migrant workers".

Therefore, we can solve this problem from the following three aspects: First,improve thefactor endowment to form the comparative advantage at a new higher level. Second, makeoverall planning, and give vigorously systematic support to strategic new industry. Third,optimize the various policies, and provide System safeguard for the coordinated development ofindustrial structure and employment structure.

\section{References}

[1] Harald Schomburg. Higher Education and Graduate Employment in Germany, European Journal of Education, Vol.3 5 ,No. 2000.

[2] Jean-Jacques Paul and Jake Murdoch. Higher Education and Graduate Employment in France, European Journal of Education ,Vol.35 ,No. 2,2000.

[3] Pryor, F and Schaffer, D. Wage and the University Educated: A Paradox Resolved. Monthly Labor Review, 1997,120(7).

[4]Gao Yanan, Zhang Boyang. Causes and Counter measures Analysis of The difficult employment of college students [J]. Youth, 2012 (5): 147

[5]Zhu Honggen, Tang Lanyuan, Chunyan. The new generation of migrant employment motivation 
empirical analysis [J]. Jiangxi Agricultural University Journal (SOCIAL SCIENCE EDITION), 2012 (2): 20 - 25.

[6]Sun Yeliang, Zhu Lihua. The analysis of labor migration and labor shortage based on labor market segmentation theory [J]2013 (1): 73 - 76

[7]Liu Zhimin. Human capital, family capital and college students employment cognitive -- Based on the empirical research in 20 colleges and universities in Jiangsu Province [J]. Journal of Renmin University of China education, 2012 (6): 129 - 145 